\title{
Los barrios con candado en el jardín de Epicuro
}

\section{María Carman}

En este artículo interesa analizar el fenómeno de las urbanizaciones cerradas, teniendo en cuenta las transformaciones que implica desde el punto de vista de las dimensiones de lo público y lo privado. Por otra parte, mi intención consiste en formular cierta teoría implícita en el ejercicio de ofrecer a otros las bondades de los barrios cerrados, que encuentro afín a los postulados de Epicuro (341-270 A.C.).

Pretendo realizar una lectura de este proceso de segregación espacial desde los postulados del filósofo griego respecto al dolor, el placer, la felicidad y la vida política ${ }^{1}$. Los invito a cruzar el espacio - las coronas de la ciudad de Buenos Aires- en busca de las urbanizaciones privadas. Y a cruzar, también, las fronteras del tiempo, en busca de los pocos rollos sobrevivientes de Epicuro, ya que la mayoría de su obra se ha extraviado.

\section{La metamorfosis del espacio}

\footnotetext{
El mundo está verdaderamente constituido cuando se forma alrededor de él una envoltura delgada, hecha con una redecilla de átomos que lo separa del espacio circundante. Si llega a romperse (...), el mundo que protegía se disgrega y sus átomos se dispersan en el vacio infinito..

Fragmento dela concepción cosmogónica de Epicuro2
}

Los barrios amurallados -también denominados clubes, pueblos privados o condominios cerrados- constituyen un fenómeno urbano de acelerada expansión en ciudades como Buenos Aires, San Pablo y México. En las zonas privilegiadas de las afueras de las grandes ciudades latinoamericanas, se cierran las calles de uso público para exclusivo disfrute de los habitantes del sector, quienes pagan un vigilante a la entrada, construyen una muralla al ingreso e imponen que sólo previa identificación

\footnotetext{
${ }^{1}$ Una primera versión de este trabajo fue realizada en 1998 y publicada tiempo después (Carman 2003). Incursiones en otros autores clásicos, y aun las mismas lecturas diez años después, me alentaron a emprender esta revisión.

${ }^{2}$ La visión moral de Epicuro se construye sobre una determinada concepción de la física. Deseamos solamente presentar al lector uno de estos principios, que curiosamente nos remonta a la imagen visual de una urbanización cerrada.
} 
alguien pueda ingresar al predio protegido, que adquiere la forma de un verdadero laberinto de características restrictivas ${ }^{3}$.

Pero cerrar un barrio no consiste solamente en levantar un muro o colocar un alambrado; no se trata de una cuestión estética ante eventuales vistas panorámicas con poco glamour ${ }^{4}$. Sofisticados dispositivos de seguridad proporcionan la libertad del paraíso $^{5}$ y garantizan su tan mentada calma chicha: alarmas, garitas, cámaras, patrullajes, rejas, tarjetas de acceso, custodias. Y aquí reside la paradoja de las murallas: la distancia física entre clases sociales se reduce -aunque es instaurada con mecanismos más complejos ${ }^{6}-$, y la distancia social se amplía.

De este modo el mundo privado se enfatiza, se acentúa en signos visibles o no de atrincheramiento, hasta volverse redundante: es el caso de una vecina de un barrio cerrado del Gran Buenos Aires que puso alarma electrónica en su casa porque, según su apreciación, en caso de robo el custodio de la entrada del barrio iba a demorar unos minutos hasta llegar allí.

En el mismo gesto en que se pretende que lo privado sea visto como público se lo vende como lo abierto, lo libre, lo natural- lo público es considerado peligroso o irrelevante $^{7}$. En tal contexto y al menos para estos habitantes, lo privado se encuentra separado de lo público, de tal modo que lo absorbe y reduce su extensión ${ }^{8}$. En efecto, fuera de los barrios con candado permanecen aquellos que nunca podrán encontrar la llave para entrar.

En un sentido similar, Silva (1992: 75-76) designa este proceso como una deformación del espacio público de la ciudad que, lejos de rechazarse y condenarse,

\footnotetext{
${ }^{3}$ El diseño laberíntico de algunas urbanizaciones cerradas dista de ser casual: el desconocido puede entrar, pero no puede salir si no conoce el mapa secreto de las vías que dan acceso a la salida, que es solamente una. El personal de seguridad provee al visitante -debidamente autorizado con anticipaciónun mapa con los recorridos circulares necesarios para encontrar la viv ienda adonde quiere arribar.

4 Algunos barrios cerrados del Gran Buenos Aires están literalmente rodeados de villas miseria; sería interesante incluir un abordaje fotográfico exhaustivo en una futura investigación sobre el tema.

5 Amendola (2000: 39) recorre la etimología del vocablo paraíso, que significa "jardín cerrado", y argumenta que el paraíso fue "el primer barrio cerrado en la historia del hombre.". En la iconografía del medioevo, agrega el autor, el paraíso siempre está representado por un jardín cerrado por muros muy elevados.

${ }^{6}$ Cfr. Caldeira 1997: 156 y Girola 2008. Algunos barrios con candado adoptan modalidades de vigilancia invisibles a los ojos de los inexpertos: sistemas de cable enterrado, rayos infrarrojos o monitoreo a distancia. Las refinadas tecnologías de seguridad de algunos barrios privados -que garantizan la exclusividad y restricción del acceso-contrastan con los límites indulgentes entre una casa y otra, apenas es bozados en es porádicos arbustos.

${ }^{7}$ Caldeira 1997: 168.

${ }^{8}$ Cfr. Duby y Ariès 1991: 16 (Tomo 5).
} 
...contagia sus resultados y hoy distintos barrios en estas ciudades siguen erigiéndose como castillos ${ }^{9}$ aislados del resto del mundo (...) la ciudad, en tan neurótica dimensión, se parece más a la guarida asediada que al espacio del beneficio colectivo.

Se trata de un mundo acotado, previsible, mientras que lo público da cuenta de un suceder, de encuentros, de posibilidades infinitas. Del otro lado de las murallas existe un mundo que se intenta dejar fuera: el del baldío, el mendigo, el ocupante ilegal, el villero; el de un peligro anónimo pero posible que se evita, pragmáticamente, autoexcluyéndose de él.

¿Y qué es lo que queda dentro? Gente de una misma clase social aunque heterogénea, compartiendo un espacio con sus propias leyes, unidos en torno a un destino similar. Estos enclaves garantizan que mundos sociales diferentes se encuentren lo menos posible en el espacio urbano: cerrar el barrio implica también cerrar el azar y la diferencia.

\section{El miedo y la libertad}

La pasión que debe tenerse más en cuenta es el miedo.

Hobbes: Leviatán

Uno podría aducir que en el barrio privado existe una ausencia de sorpresa, expresada tanto en decisiones éticas -el deliberado autoencapsulamiento que impide el encuentro con los sin techo o cartoneros- como en decisiones estéticas: la homogeneidad estructural de las fachadas. El azar, sin embargo, podría cruzar nuestro destino con, por ejemplo, una liebre. ¿Pero es la liebre u otro animal salvaje la única sorpresa posible en la inercia nocturna (o el predecible movimiento diurno) del barrio cerrado?

\footnotetext{
${ }^{9}$ Silva (1992: 75-76) remarca el sentido de castillo que viene tomando el diseño de vivienda de estos barrios exclusivos, rodeados de todos los posibles instrumentos de seguridad. La comparación resulta visualmente acertada. Incluso podemos adentrarnos en otros elementos que nos sugiere la noción de castillo, co incidente con las características de estos barrios cerrados: la fosa -el alambrado que lo aísla del mundo externo-, y el puente levadizo: una única entrada posible, para imped ir el paso del enemigo.
} 
Ciertamente no lo es. Entre bambalinas trasciende el desasosiego de los vecinos frente a los inadmisibles atropellos de adolescentes del propio barrio, fundamentalmente hurtos. Se trata de un mensaje en cuya traducción no se ahonda, como tampoco se denuncia frente a las autoridades policiales, sino que se resuelve dentro de las instancias disciplinarias internas del barrio ${ }^{10}$. Esta significativa renuencia, por parte de los pobladores de los barrios privados, de que intervengan las fuerzas públicas en caso de delitos perpetrados por residentes o "invitados"-como ellos denominan a los amigos de sus hijos- se invierte drásticamente cuando los responsables de los delitos son "externos" al barrio, o bien personal interno contratado: empleadas domésticas, custodios. La intervención policial o judicial es justificada, entonces, no por la calidad de visitante del acusado, sino por la clase social a la cual adscribe.

En un exclusivo barrio privado del gran Buenos Aires, unos adolescentes habían arrojado simbólicamente los aparatos electrónicos que habían hurtado de diversas casas -televisores, videos- dentro de una bañadera llena de agua de otra casa. Luego de este episodio perturbador ${ }^{11}$-sumado a la misteriosa desaparición de una costosa computadora portátil en otro domicilio-, algunas vecinas del barrio me comentaron que comenzaron a cerrar con llave la entrada de sus casas, que antes permanecían abiertas. Lo interesante es que, si bien fue comprobado que estos delitos fueron cometidos por los adolescentes del barrio o sus amigos no residentes, las únicas que fueron sometidas a requisas intimidatorias a la entrada y salida del barrio fueron las empleadas domésticas.

Una empleada doméstica me relató que estaba obligada a declarar, en la entrada del barrio cerrado, los objetos personales con los que acudía a trabajar a las casas: su ropa, sus libros o discos compactos. En caso de que olvidara declararlos, ya había tenido repetidos problemas por la suposición automática por parte del personal privado de seguridad de que los había sustraído de la casa en cuestión, con lo que solo lograba salir de la fortaleza privada cuando su "patrona" intercedía ${ }^{12}$.

Un colega antropólogo también me comentó cómo, viajando en la camioneta de una empresa privada que realiza el trayecto de los barrios cerrados de Pilar a Buenos

\footnotetext{
10 Algunos barrios privados cuentan con tribunales de disciplina que, ante las denuncias de mal comportamiento de socios o invitados (robos, peleas, exceso de velocidad) aplican sanciones que incluyen suspensiones, o incluso la prohibición de ingreso.

${ }^{11}$ El gesto didáctico recuerda al film alemán Los Edukadores, en el cual el grupo homónimo de jóvenes entraba en residencias de clases acomodadas, desactivaba alarmas y cambiaba los muebles de lugar, dejando una nota con el siguiente mensaje: Usted tiene demasiado dinero.

12 Cuanto mayor es la presión sobre la propiedad privada, aumenta proporcionalmente la privatización de la seguridad, que no es sino una privatización de la coerción y, en última instancia, del contrato social: la función que debería cump lir el Estado pasa a manos privadas.
} 
Aires, esta se detuvo en la entrada de una urbanización donde habían subido varias empleadas domésticas. El guardia de seguridad vociferó entonces de mal modo:

- “QQue bajen dos domésticas!"

Pero nadie se movió de su asiento. El chofer miraba para atrás en silencio. El grito se repitió y entonces, como la camioneta iba a permanecer detenida hasta no completar la requisa al azar, la extorsión operó y dos mujeres, de mala gana, descendieron y dejaron que los guardias revisen sus pertenencias, tras lo cual volvieron a subir y la camioneta continuó su recorrido. Cabría preguntarse frente a estas prácticas de sesgo carcelario si, como diría Hobbes (1994 [1651]:174), el miedo y la libertad son compatibles, o bien sobre los límites éticos de construir el sueño de libertad de unos por sobre la libertad de otros.

Si las clases media y alta son concebidas como "auténticas" portadores de miedo, los sectores populares ni siquiera son percibidos, en ocasiones, como sujetos dotados de agencia. No obstante, frente al miedo y la violencia consagrados se alzan otros miedos o violencias invisibles, como las intimidaciones que ejercen los guardias públicos o privados sobre los sectores populares.

\section{El naturalis mo, la propiedad privada y la beneficencia}

El hecho de vivir en barrios con candado construye representaciones del mundo legítimo que desalientan la empatía y el contacto con aquellos que nunca podrán vivir allí. Lo que se quiere evitar, presumo, es el ser mirado por otros que devuelven con sus cuerpos y manos gastados por el hambre, o un duro trabajo físico- el problema de la existencia de las desigualdades sociales: éstas se tornan demasiado visibles y resultan obscenas. Acaso esta misma circunstancia aliente la beneficencia privada tan difundida entre los residentes de barrios cerrados, y en particular de los más exclusivos. La poderosa correspondencia entre la defensa de la propiedad privada y aquello que Girola (2008) denomina mordazmente la gestión privada de la solidaridad, ya está presente en la obra de Joseph Townsend (1739-1816).

Veamos de qué modo la fuga hacia el naturalismo de Townsend sostiene como principal argumento el resguardo de la propiedad. Para Townsend, los hombres no son como bestias, según sostenía Hobbes (1994) [1651], sino que son efectivamente bestias, 
y precisamente por esa razón sólo se requiere un mínimo de gobierno. Desde su punto de vista novedoso -basado en el célebre teorema de las cabras y los perros-, una sociedad libre podía considerarse integrada por dos razas: la de los propietarios y la de los trabajadores. El número de estos últimos estaba limitado por la cantidad de alimentos; y mientras que la propiedad estuviese segura, el hambre los impulsaría a trabajar. Con un énfasis que evoca la cobertura de cierta prensa respecto al abuso ${ }^{13}$ de las usurpaciones, Townsend arguye que el hombre debe ser castigado cuando invada la propiedad de su vecino. Respecto al principio de la beneficencia, sugiere el autor:

\begin{abstract}
¿Y no son mucho más nobles los sentimientos caritativos que los derivados de obligaciones legales estrictas? ¿Podrá haber en la naturaleza algo más hermoso que la complacencia moderada de la benevolencia?

Townsend citado en Polanyi (2003) [1957]: 165-170.
\end{abstract}

No resulta azaroso que dos periódicos nacionales dediquen un suplemento semanal a difundir las bondades -jamás los sinsabores- del estilo de vida country. Dicho estilo pondera una moralidad distanciada de aquellos que carecen de vivienda o trabajo estable -y cuyo ocio tampoco puede ser definido en los mismos términos de goce y disfrute. Uno de estos periódicos, cuya línea editorial privilegia a ultranza la defensa de la propiedad privada, dedica también un suplemento a las iniciativas solidarias.

Polanyi (2003 [1957]: 165-170) sostiene que los economistas renunciaron pronto a los fundamentos humanistas de Adam Smith e incorporaron los de Townsend, publicados en Dissertation on the Poor Laws (1786), pocos años después de La riqueza de las Naciones (1780). La naturaleza biológica del hombre aparecía aquí como el fundamento dado de la sociedad. Townsend, en efecto, introdujo un nuevo concepto de la ley en los asuntos humanos: el de las leyes de la naturaleza, que correspondían muy bien, como sostiene Polanyi, a la sociedad que estaba surgiendo.

\title{
¿El te mor lo justifica todo?
}

\footnotetext{
13 "Los abusos [de las ocupaciones ilegales] han llegado a tal extremo que (...) podía ser visto un improvisado albergue levantado en un mímimo retazo de césped de la avenida 9 de Julio (...), pues la ciudad está cada vez peor en este sentido" (Nota editorial La Nación, 10/9/2005. El resaltado es mío).
} 


\author{
...suave cosa es contemplar aquellos males de \\ los que tú careces. Dulce, también, mirar \\ grandes contiendas de guerra desplegadas por la \\ campiña, sin peligro alguno de tu parte. (...) ¿No \\ veis que la naturaleza no reclama otra cosa sino \\ que se aleje el dolor del cuerpo y que la mente \\ disfrute de alegres sensaciones, eliminando el \\ cuidado y los temores? \\ Lucrecio: De rerum natura \\ No se teme lo que está muy lejos. \\ Aristóteles: Retórica
}

¿No hay en el origen de estos barrios cerrados un temor, una oscuridad indecible, vinculada al poder sufrir una herida por alguien que a su vez sufre? ¿Y al hecho de saber que el sufrimiento del otro no es ajeno al propio bienestar? Podemos interpretar la mudanza a estos barrios fortificados como un gesto desesperanzado de abolir la desigualdad; aunque en rigor, estos modos de segregación urbana no hacen sino volver la desigualdad más explícita ${ }^{14}$.

Si una vasta proporción de proyectos inmobiliarios $-\mathrm{y}$ sus publicidades directas e indirectas- procura instaurar un orden a partir del miedo al espacio considerado excesivamente público, ¿es válido inferir que los clientes de tales proyectos motivan su decisión de mudarse a un barrio privado por idéntico motivo?

Para gran parte del pensamiento alemán, el hombre es un ser habitado por una angustia primordial - la angustia de ser en el mundo y saberse mortal-, que conduce a esta filosofía a percibir a los hombres y a las sociedades como "...energías fabricadoras de estabilidad, de orden, de valores y de sentido" (Méda 1995: 232). Una primera interpretación de este fenómeno apunta a que la construcción de estas fortalezas, dentro y fuera de la ciudad capital, responden básicamente a la amenaza, a la violencia latente. Incluso autores como Amendola incurren en tal reduccionismo:

Es este temor, a veces extraordinario por su intensidad y radicación, el que permite comprender formas urbanas y arquitectónicas, comportamientos y posturas adaptativas, asumidas por aquel flâneur espantado que es el hombre metropolitano contemporáneo.

Amendola 2000: 317.

\footnotetext{
${ }^{14}$ Cfr. Caldeira 1997: 174.
} 
En términos de Hobbes (1994 [1651]: 117), se trata de un convenio perfectamente válido, en tanto se realiza a partir del miedo. ¿Es posible hablar entonces de un mero mecanismo reactivo: refugios compensatorios frente a las "usinas de miedo"?

Investigaciones empíricas recientes echan por tierra esta hipótesis. Si bien un porcentaje menor de los actuales residentes de los barrios privados aduce haberse mudado luego de sufrir un episodio violento, la mayoría de los pobladores esgrime motivos que recorren un amplio espectro entre lo puramente económico, el placer del "verde", y la crianza relajada de los niños ${ }^{15}$.

Si bien no figura entre los motivos admitidos, la mudanza a los barrios cerrados también se vuelve inteligible como un gesto de aquellos "ciudadanos plenos" para distanciarse física y moralmente de los "indeseables".

\section{"Vive Oculto" ${ }^{16,}$}

Frente a las demás cosas es posible procurarse seguridad, pero frente a la muerte todos los hombres habitamos una ciudad sin murallas.

Frg. 339 Usener, Epicurea, Leip zig, 1887

¿En qué sentido es posible referir la experiencia colectiva de progresivo poblamiento de barrios privados como un fenómeno ligado a preceptos epicúreos?

Epicuro retoma una cuestión clave de la ética griega, ya presente en el Filebo de Platón y la Ética Nicomaquea de Aristóteles: la preocupación acerca de cuál es la mejor manera de vivir para el ser humano. Se trata de una ética de la felicidad -bien distante de la ética del deber kantiana- que se interroga acerca de cuál es la función del placer en la felicidad (eudaumonia $)^{17}$. Para Aristóteles, la felicidad se logra conforme a la virtud; comparece en su obra un nítido horizonte de lo colectivo y el sentido de la justicia.

\footnotetext{
${ }^{15}$ Cfr. Capron, Girola y Lacarrieu (2005).

${ }^{16}$ Célebre precepto epicúreo, ta mbién traducido co mo "vive en secreto".

${ }^{17}$ Como señala Pinkler (1998) retomando el análisis de Nietszche, se trata de una estética de la existencia contrapuesta a la moralización de la existencia cristiana: si en este mundo están todos los mundos posibles, la propia existencia ha de convertirse en una obra de arte.
} 
La solución epicúrea a este dilema -antiaristotélica, y también antiplatónica por su visión materialista- no conduce a la virtud, sino al placer que es experimentado a través de los sentidos. Lejos, también, del héroe homérico que acepta su destino trágico, en Epicuro el placer constituye el principio y fin de la felicidad. Los epicúreos se esforzaban por huir del temor, y la felicidad se basaba en su eliminación. Esta dimensión subjetiva de la felicidad florece, no azarosamente, en paralelo al quiebre del marco de la ciudad, que constituía el punto de referencia para el griego ${ }^{18}$.

Siguiendo a Long (1977: 78), podemos afirmar que Epicuro nunca insinúa que el interés de los demás haya de ser preferido o valorado independientemente del interés del sujeto: "En una época de inestabilidad política y de desilusión privada, Epicuro vio que la gente, como los átomos, son individuos, y que muchos de ellos andan vagando en el vacío". Según Epicuro, los seres humanos no poseen tendencias naturales hacia la vida comunitaria. Su concepto de justicia -basado en un pacto de no hacer ni sufrir daño- no presenta obligaciones morales ni sociales. La justicia de Epicuro nos requiere a que respetemos los derechos de otros sólo si resulta ventajoso para todas las partes afectadas. Vale decir que la base de este reconocimiento se asienta en el propio interés ${ }^{19}$.

Los seguidores de Epicuro fueron conocidos como los filósofos del jardín ya que se congregaban en jardines de los cuales, según la leyenda, colgaba la siguiente inscripción: "Forastero, aquí estarás bien. Aquí el placer es el bien primero".

Es sabido que Epicuro era un enfermo crónico grave que sufría intensos dolores. Según Nietzsche, sólo alguien que sufría constantemente pudo inventar felicidad semejante ${ }^{20}$. Retomando también este factor psicológico personal de Epicuro, Cicerón observa con cierta malicia: "no he visto a nadie que haya temido tanto como Epicuro lo que él niega que sea terrible: es decir, la muerte ${ }^{21 "}$.

Esta supuesta anulación del temor le otorga, en rigor, un papel fundamental al propio temor. Algo similar podríamos sostener respecto a los moradores de los barrios

\footnotetext{
${ }^{18}$ En este punto, Epicuro se distancia también de Sócrates: no procura dejar a las nuevas generaciones una ciudad mejor. Para un análisis más detallado de la relación entre la crisis de la ciudad y las nuevas corrientes de pensamiento en el siglo III en Grecia, cfr. Festugière 1960 y García Gual 1996: 7-40. Coincidimos con Pinkler (1998) en que el epicureís mo parece ser una filosofía adecuada para mo mentos de la hu manidad en que se derrumban los grandes ideales.

${ }^{19}$ Cfr. Long 1977. "El sabio del siglo III es un ser 'que se basta' (...) Se esfuerza por hacerse indiferente, 'insensible' a todo cuanto proviene del exterior" (Festugière 1960: 7).

${ }^{20}$ Citado por García Gual 1996: 164. Toda su filosofía, en efecto, busca eliminar la angustia humana (Long 1977: 56). Michaux (1988) diría que este sistema filosófico no es sino un exorcismo por ardid: en el lugar mismo del sufrimiento se introduce tal exaltación, que el daño se disuelve progresivamente.

${ }^{21}$ De nat. Deorum, I, 31, 86 citado por García Gual 1996: 183.
} 
cerrados: el aislarse de los peligros de lo público no hace sino reforzar el miedo inicial. ¿No son ahora, los de afuera, doblemente extraños?

\section{¿Un placer inmutable?}

(...) todo placer es un bien por su conformidad con la naturaleza (...) nunca, ni despierto ni en sueños, sufrirás turbación, sino que vivirás como un dios entre los hombres.

Epicuro: Carta a Meneceo, D. L. X, 130-135.

Podemos establecer cierto paralelo entre la elegante simplicidad de la ética de Epicuro (Long 1977) y aquella indolente de las publicidades de los barrios privados y aun de los discursos de sus moradores famosos, tal como son presentados por los suplementos ad hoc de diarios nacionales desbordados de anunciantes.

A tono con el epicureísmo, las publicidades de los barrios privados apuestan al ideal del placer estable:

\footnotetext{
"iSus fines de semana ahora son de siete días!"

"La felicidad permanente para niños, adolescentes y adultos ${ }^{22} "$.

"Vivir aquí será su inmenso placer de cada día".
}

Para Epicuro la muerte no nos concierne pues mientras existimos, ella no está presente. Emuladores de Epicuro, estos anuncios enfatizan la belleza y esconden la decadencia que ya trabaja en cada célula de nuestro cuerpo, desde que nacemos, encaminándonos hacia la muerte, lo único seguro en nuestras vidas.

El placer que promueve Epicuro no apunta al goce desenfrenado de un acontecimiento único, sino al goce constante de la vida ordinaria. La mudanza a los jardines amurallados contemporáneos es alentada desde un horizonte similar: encontrar, a partir del placer, una serenidad. Epicuro define el placer en términos negativos, articulado al ideal de a-taraxia (imperturbabilidad): no sufrir dolor en el cuerpo ni turbación en el alma. Como señalan García Gual y Acosta Mendez (1974:73), se podría calificar de apolíneo el talante de la felicidad buscado por Epicuro: es el cálculo prudente, el placer cotidiano el que da sentido a la vida. Ahora bien, la austeridad de los

\footnotetext{
22 Al igual que algunos ritos de institución, estas publicidades construyen la idea de una familia unida, estable, del lado de lo natural y lo universal, o bien en términos de una ficción bien fundamentada (Bourdieu 1998: 60-61).
} 
placeres perseguida por Epicuro contrasta con la falsa apelación a la sencillez de estos emprendimientos privados, en los que el lujo es sublimado y presentado como la mera culminación de un "estilo de vida". Se oblitera, en síntesis, el difícil acceso a tal estilo de vida.

Es innegable que Epicuro insistía en la naturalidad y facilidad para procurarse el placer, pese a que sus jardines constituían el privilegio de una minoría. Creo necesario formular, no obstante, algunos reparos a las interpretaciones tradicionales de su legado ${ }^{23}$. En primer lugar, la concepción del placer de Epicuro no remite, como se ha consolidado en el sentido común, a un hedonismo exacerbado. Nada más lejos de la búsqueda de moderación de nuestro entrañable ateniense, que discernía entre placeres necesarios e innecesarios, tomando distancia del intenso sensualismo de Aristipo. En segundo lugar, es importante aclarar que solo estamos retomando, a los fines de esta analogía, un conjunto acotado de los postulados de Epicuro, omitiendo toda mención a sus conmovedores juicios sobre la amistad, la sabiduría o la naturaleza.

Aquí estoy simplemente sugiriendo cierto sustrato filosófico implícito en el fenómeno urbano que supone la multiplicación abrumadora de barrios con candado en el Gran Buenos Aires, y en nuestras ciudades latinoamericanas. Por lo tanto, no aludo a la relación de ciertos actores con el dolor y el placer individual sino en términos sociales o, si se prefiere, en términos de dispositivos. Y es en este sentido en que interesa interrogar respecto a las consecuencias no buscadas de la acción (Giddens 1995: 39-64) de múltiples actores en relación a su elección personal de vivir en un barrio cerrado.

El emprendimiento comercial de los barrios privados retoma un malestar social respecto a la supuesta condición excesivamente pública de la vida en la ciudad, y proporciona una respuesta categórica: el mundo de la naturaleza y la seguridad aunque esta dupla suene irónica- donde ya no hay qué temer, y donde uno puede protegerse de la mirada de los demás.

\footnotetext{
${ }^{23}$ La recepción moralista del epicureísmo objeta a esta filosofía su "atmósfera igual y sonriente de medio cerrado", ante cuyos límites se detienen los males del exterior (Rivaud 1962: 305-308). Este autor le reprocha a la filosofía de Epicuro su falta de altruis mo y el hecho de que empobrezca las almas "...para no conservar en ellas sino lo placentero y agradable"; calmando "...su angustia mediante el rechazo de todo compro miso radical". Y concluye, enfático: "El epicureís mo (...) amputa deliberadamente de su vida todo lo que podría ser prueba o catástrofe. (...) Hay algo artificioso en esa alegría voluntaria y en esa mediocridad sabiamente cultivada". En un tono similar, Maritain (1966: 94-98) argu menta que la perfecta indiferencia de los epicúreos, sin el vaho de sudor humano que exhala la fuerza estoica, concluye en un sueño evasivo de las profundas realidades de la vida. Agradezco a Marcos Guntin sus valiosos aportes y la entusiasta traducción de Sententiae Vaticanae (Cyril Bailey, Epicurus. The Extant Remains. Clarendon Press, Oxford, 1926).
} 
Si bien la mención a la seguridad nunca está ausente en las publicidades de los barrios cerrados, existe cierta pretensión de sublimarla porque ya está sobreentendida en la noción de barrio cerrado y, en segundo lugar, porque el peligro sólo es aludido en giros que tácitamente suponen a un otro considerado enemigo. "Vecindad excelente", "entorno asegurado", "vigilancia electrónica única", "seguridad las 24 horas", son algunas de las indirectas alusiones a un otro potencialmente riesgoso ${ }^{24}$. En tercer lugar, la mención a la seguridad se ve sublimada porque la lucha por la última diferencia legítima ${ }^{25}$ entre los barrios cerrados se desplaza a la arena más legítima de la naturaleza.

La búsqueda de distinción se traslada al reino animal -una publicidad menciona la presencia de centenares de ciervos axis- o a deportes exóticos pero no por eso menos naturales: aéreos, marinos, hípicos. Las publicidades también resaltan aquellos barrios que tienen arboledas añosas, mayor variedad o cantidad de especies vegetales o mayor acervo patrimonial, incluyendo historias míticas y leyendas. La historia -simbolizada en sus árboles o en sus antiguos moradores, como en el caso de algunos barrios cerrados asentados sobre cascos de estancias- les procura a estos emprendimientos comerciales un anclaje en algún sitio, aunque más no sea en las raíces de su vegetación. Incluso algunos folletos de barrios cerrados exhiben imágenes de árboles allí donde no existen todavía, desafiando las leyes del tiempo, como si ya fuesen ejemplares adultos; mientras que, tan sólo meses atrás, la vacas pastaban en ese mismo predio: una gran llano desprovisto de árboles.

En los emprendimientos comerciales de las urbanizaciones cerradas, la naturaleza se construye como antítesis del miedo. En efecto, pareciera que una abundancia de naturaleza eliminaría el miedo, la inseguridad, la pobreza, aunque no es cualquier naturaleza la que puede albergar a la humanidad deseada ${ }^{26}$. Concebida de este modo, la naturaleza legítima se alza como un instrumento para apaciguar conflictos. Vivir de acuerdo con la naturaleza, diría Epicuro, permite el goce continuo de la propia felicidad e incorruptibilidad.

\footnotetext{
${ }^{24}$ Co mo demuestra Hobbes (1994: 105-266) en su tratado del Leviatán, el temor refiere a un otro que es vis to como un enemigo. (Cfr. ade más Bau man 1994: 44-57).

${ }^{25}$ Bourdieu 1997: 227-237.

${ }^{26}$ Amén de los espacios verdes de los barrios privados del Gran Buenos Aires, se alzan otras naturalezas legítimas en el radio de la ciudad: la naturaleza "salvaje" de la Reserva Ecológica (aunque cercana al centro neurálgico del poder político y económico del país); y la naturaleza debidamente controlada de las nuevas y exclusivas plazas de Puerto Madero, en los alrededores de los edificios torres.
} 
El acceso a esa solución estaría garantizado por la simple portación de atributos naturales ("Si está buscando un lugar mejor para vivir, respire ${ }^{27}$ "), o bien comportamientos culturales concebidos como naturales: "Estrenalo". "Invertí bien. Viví mejor". Por otra parte, es interesante comentar una nueva generación de urbanizaciones cerradas de la Patagonia Argentina - los llamados Eco Countries o Barrios Verdes- que "se inscribe en la filosofía del respeto por el medio ambiente" (Clarín, 27/6/2009). En estos nuevos complejos -que incluyen reservas naturales, montañas propias y hasta jardines botánicos- se promociona "el cuidado de la naturaleza a perpetuidad con un mínimo de impacto ambiental" (Ibíd.).

Si en tales ofrecimientos la naturaleza se convierte en una suerte de bien patrimonial, en otros se acentúa una visión comunitaria que remite a una visión idealizada del barrio de antaño: "Rodeado de barrio. De barrio de verdad. Tu barrio". Algunos autores contemporáneos sostienen que los habitantes de los barrios privados proclaman una suerte de cultura de la segregación (Bernard 1994: 76), reivindicando su solidaridad y cohesión social. No coincidimos, sin embargo, con el urbanismo afinitario (Donzelot 1999) imputado a la sociabilidad existente en dichas urbanizaciones, pues dicho supuesto nos aleja de la experiencia quizá más significativa de sus moradores: aquello que Girola (2008) sintetiza como una heterogeneidad conflictiva.

En el radio de la ciudad, las torres-country de Puerto Madero recurren al valor agregado de su cercanía a la Reserva Ecológica ${ }^{28}$ para promocionar sus proyectos:

\begin{abstract}
"Abrir una ventana y ver el río. Caminar hacia nuevos horizontes. (...) Puerto Madero encuentra su reposo en una reserva ecológica de 350 hectáreas, donde habitan la flora y la fauna característica de la ribera rioplatense. (...) Bienvenido a Le Parc Puerto Madero. (...) Un nuevo estilo de vida lo espera. Adelántese”.
\end{abstract}

\footnotetext{
${ }^{27}$ El simple hecho de respirar puede encuadrarse entre los placeres catastemáticos (en reposo) que venera Epicuro.

${ }^{28} \mathrm{La}$ "naturaleza pura" de la reserva deviene -en sus estrategias publicitarias - un artefacto funcional a las leyes del mercado: ninguna otra torre del mercado de la ciudad puede ufanarse de tener al alcance de la mano tantas hectáreas vírgenes. Si Puerto Madero es, en lo esencial, una sumatoria de torres-country, no es descabellado suponer que este barrio porteño aspire a funcionar como una suerte de inmensa urbanización privada.
} 
La expresión ya dice todo respecto a quienes quedan afuera, en tanto “...los únicos dotados de un 'estilo de vida' serían las clases dominantes” (Grignon y Passeron 1991: 119). Esta "elección de vida" es presentada bajo una apariencia sencilla, casi automática: "Saque el pie del acelerador", reza uno de los afiches sobre la autopista Buenos Aires-La Plata que instan a mudarse a un barrio privado.

$\mathrm{Y}$ es que las barreras materiales de los barrios amurallados también sirven para excluir, metafóricamente, a las clases populares de la esfera de la cultura y de la sociedad incluso (Grignon y Passeron 1991: 113). Pues las clases sociales

\begin{abstract}
...no se distinguen únicamente por su diferente capital económico. Al contrario: las prácticas culturales de la burguesía tratan de simular que sus privilegios se justifican por algo más noble que la acumulación material (...) La burguesía desplaza a un sistema conceptual de diferenciación y clasificación el origen de la distancia entre las clases. Coloca el resorte de la diferenciación social fuera de lo cotidiano, en lo simbólico y no en lo económico, en el consumo y no en la producción. Crea la ilusión de que las desigualdades no se deben a lo que se tiene, sino a lo que se es. La cultura, el arte y la capacidad de gozarlos aparecen como "dones" o cualidades naturales, no como el resultado de un aprendizaje desigual de la división histórica entre las clases.
\end{abstract}

García Canclini 1990: 25.

Queda claro que Epicuro no buscaba combatir el statu quo ni transformar la sociedad. Los barrios privados, por su parte, no pretenden solucionar el "caos" de la ciudad, sino ofrecer un confortable refugio. Quizás no sea temerario suponer que ambas experiencias, de sesgo defensivo, constituyen una ética de limitación (García Gual et al. 1974: 83). Al igual que los cínicos, Epicuro considera a la autosuficiencia la mayor de todas las riquezas. La autarquía que conquistan los epicúreos es, sin embargo, dudosa, pues las sensaciones placenteras necesitan siempre de un objeto agradable y dependen de los bienes delexterior (Ibíd.).

Recordemos además el pacto de no hacer ni sufrir daño que cifra el ideal de justicia epicúrea. En el marco de esta ética de limitación, alcanzaría con procurar no ser dañado por los demás ni causar, como sostiene Epicuro, preocupación a otros. En el caso de las urbanizaciones cerradas, algunos pobladores defienden su elección 
aduciendo, precisamente, que con ella no dañan a nadie, y que incluso realizan beneficencia en las villas próximas.

El gesto de repliegue expresa la ilusión de "irse del mundo", de no formar parte del mundo público violento de allá afuera, el de los diarios o noticieros. Pero no existe tal posibilidad de no formar parte y esta es la gran contradicción de las clases medias y altas que como ironiza Caldeira (1997: 161), arman su sueño de independencia y libertad en base a los servicios prestados por los trabajadores pobres. Toda una legión de guardias de seguridad, empleadas domésticas, baby-sitters, jardineros, pileteros por lo general -como afirma Caldeira- mal pagos, y que muchas veces viven en las villas contiguas al barrio cerrado ${ }^{29}$.

Por más que algunos moradores de urbanizaciones privadas reproduzcan su existencia en una serie de de circuitos controlados, en los cuales la sociabilidad ideal es la que transcurre de un lado de las murallas ${ }^{30}$, el "otro" irrumpirá de un modo u otro. De hecho ya irrumpe en un lugar curioso: al interior del propio barrio, como un caballo de Troya.

En un contexto de miedo creciente al crimen, en que los pobres son asociados a la criminalidad, las clases medias y altas temen el contacto y la contaminación, pero continúan dependiendo de sus empleados (...) [manteniendo con ellos] relaciones tan ambiguas de dependencia y evitación, intimidad y desconfianza.

Caldeira 1997: 161. La traducción es mía.

De esta paradoja ya hablaba Hegel en su célebre dialéctica del señor y el siervo: los señores anhelan un mundo de iguales pero dependen del trabajo del otro, y fracasan en su intento de alcanzar la libertad. Según Hegel, el señor nunca va a ser un ser independiente, para sí, en la medida en que depende de otro ser, de la acción de aquel que trabaja para él. Como corolario de su dialéctica, Hegel concluye que el señor,

\footnotetext{
29 También hay casos de empleadas domésticas que van a trabajar a las urbanizaciones cerradas los fines de semana pese a que vivan en el otro extremo del Gran Buenos Aires; recorriendo grandes distancias a pie entre la parada del colectivo en la autopista y la entrada del barrio privado. Estos "otros" que ingresan al barrio privado, a pesar de ser sus empleados, son requisadas aun bajo la lluvia y en invierno, mientras que por la entrada contigua ingresan los propietarios en auto, saludando por la ventanilla.

30 Algunos barrios privados basan su estrategia publicitaria en que los nuevos propietarios no necesitan salir del barrio para mandar a sus hijos a la escuela, porque la escuela -bilingüe y doble turno-ya está allí dentro. Otros barrios incluyen dentro de sus servicios jardines maternales, colonia infanto juvenil, torneos deportivos, reuniones y bailes.
} 
al no transitar por el camino del dolor, nunca llegará a ser verdaderamente libre. En esta relación de reconocimiento unilateral y desigual, son precisamente los siervos -al estar, ellos sí, en arduo contacto con las materias del mundo- los que experimentan temores ancestrales, profundas experiencias de dolor y muerte ${ }^{31}$.

\title{
Epílogo
}

\author{
(...) la seguridad más límpida (...) procede de la \\ tranquilidad y del apartamiento de la \\ muchedumbre.
}

Epicuro: Máximas capitales (D.L., X, 139-154)

Los barrios privados se enarbolan como residencia ideal de aquellos que detentan una "humanidad plena": se trata de buscar una salida individual a un malestar fundado en el temor, y encontrar un jardín fuera de las miradas ásperas de los otros. En el ofrecimiento comercial de estos paraísos subyace una teoría del placer: aquella que enunciara Epicuro -otro pragmático- para enseñar a los hombres un camino a la felicidad.

Así como los discípulos de Epicuro buscaban en su filosofía un abrigo contra el dolor, los habitantes de los barrios cerrados -que se multiplican actualmente como florecían, en aquella época, los jardines de Epicuro- buscan un abrigo contra los peligros foráneos. Los barrios privados son la metáfora de un mundo que no quiere contactarse con el dolor que hay detrás de la belleza.

Vimos también que los sectores medios "abandonan" la ciudad -o lo que ella tiene de impredecible, de inmanejable- motivados no solo por el miedo. Cabría preguntarnos si esta renuencia a "habitar" el azar de lo público no conduce - por usar la perturbadora expresión de Méda (1995: 244)-, a “... formas de alienación aun peores de las que conocemos".

Mi último pensamiento se dirige a las nuevas generaciones. ¿Qué ha de suceder con aquellos que están naciendo y criándose dentro de los barrios cerrados y sus cajitas

\footnotetext{
${ }^{31}$ La temática es a todas luces compleja, por lo que nos conforma mos con esta breve mención. No deja de resultar una ironía que culmine este "capítulo epicúreo" citando a Hegel, que despreciaba el materialis mo de Epicuro (Inversamente Marx, admirador de su obra, dedicó a Epicuro y Demócrito su tesis doctoral). Para un análisis más exhaustivo de la dialéctica del señor y el siervo ver Hegel 1973: 117-121; Marcuse 1970: 114-121 e Hypollite 1974: 154-160. Para una lectura de la dialéctica hegeliana en relación a la problemática del temor, ver Valls Plana 1979: 128-160.
} 
chinas: el colegio, el club house y todo el mundo aparte que se pretende armar intramuros?

Recuerdo un film sobre la vida de Siddharta, en el cual el príncipe ha sido criado en un ambiente alejado de cualquier signo de tristeza o decrepitud. Un día pasea en un carro y detrás de sus siervos ve, fugazmente, la figura de un anciano enfermo. Le pregunta a su padre por él, ya que desconoce el significado de las palabras pobreza, enfermedad y vejez; y luego sale al mundo a encontrarse con las experiencias nombradas por esas palabras ignoradas. ¿Saldrán ellos también al mundo extramuros de ágoras, diferencias y desigualdades? 